\title{
Disputas por el derecho a la educación y la educación pública en América Latina: políticas, instituciones y sujetos en la gubernamentalidad neoliberal
}

\begin{abstract}
Disputas pelo direito à educação e educação pública na América Latina: políticas, instituições e sujeitos na governabilidade neoliberal Disputes over the right to education and public education in Latin America: policies, institutions and subjects in neoliberal governmentality
\end{abstract}

MARÍA ELENA MARTÍNEZ Orcid Id: http://orcid.org/0000-0002-8580-0300 Universidad Nacional de La Plata - Argentina.

VIVIANA ISABEL SEOANE

Orcid Id: http://orcid.org/0000-0002-8702-7147 Universidad Nacional de La Plata - Argentina.

\begin{abstract}
Resumen: El neoliberalismo está dominando la vida político-institucional y social de las democracias latinoamericanas, cambiando la concepción de lo político. La gubernamentalidad neoliberal produce renovadas formas de mercantilización y privatización en la educación pública, imponiendo modelos empresariales a la gestión escolar y reestructurando las relaciones de trabajo en el sistema educativo. Estos cambios en las estructuras y formas de gobierno de la educación se orientan a producir subjetividades sumisas, impidiendo cualquier forma de crítica en el campo de la educación.
\end{abstract}

Palabras clave: Democracia. Neoliberalismo. Educación pública. América Latina.

Resumo: O neoliberalismo está dominando a vida politico-institucional e social das democracias latinoamericanas, transformando a concepção do que é político. A governabilidade neoliberal produz novas formas de mercantilização e privatização na educação pública, impondo modelos empresariais à gestão escolar e reestruturando as relações de trabalho no sistema educativo. Essas mudanças nas estruturas e formas de gestão da educaşão produzem subjetividades submisas, impedindo qualquer forma de crítica no campo da educação.

Palavras-chave: Democracia: Neoliberalismo; Educaşão Pública; América Latina. 


\begin{abstract}
Neoliberalism is dominating the political-institutional and social life of Latin American democracies, changing the concept of politics. Neoliberal governance produces renewed forms of commercialization and privatization in public education, imposing business models on school management, and restructuring labor relations in the education system. These changes in the structures and forms of government of education are oriented to producing submissive subjectivities, preventing any form of criticism in the field of education.
\end{abstract}

Keywords: Democracy. Neoliberalism. Public education. Latin America.

\title{
DESARROLLO
}

Hacia finales del año 2018 un medio de prensa hegemónico de orientación conservadora publicaba en Argentina una noticia bajo el título "La democracia pierde atractivo en la región: la mayoría no la prefiere como forma de gobierno". Su redactor afirmaba que, según el sondeo anual de Latinobarómetro, "sólo una minoría de la población de los países de nuestra región consideraba a la democracia como una forma preferible de gobierno". Basándose en esa encuesta de opinión, presentaba como ejemplos que solamente un 34\% de los habitantes de Brasil y un 38\% de México se inclinaban por la democracia como forma de gobierno, en tanto que, al resto de la población de esos países, les resultaba indistinto vivir bajo un régimen democrático o bajo uno no democrático o autoritario.

Este texto periodístico expone, sin eufemismos, el punto de vista de los sectores dominantes en América Latina que se proponen difundir e imponer una visión de los pueblos de la región como indiferentes o desinteresados con respecto a los regímenes políticos democráticos. Estos mismos sectores, a la vez, han venido incesantemente desarrollando estrategias para debilitar a los Estados a lo largo de varias décadas, a fin de cambiar la base de sustentación política de los estados democráticos que no será ya la voluntad popular, sino los intereses del establishment financiero y económico global.

Desde mediados del siglo XX, como afirma Brown (2017, p. 5), estos grupos se han propuesto apropiarse del Estado para hacerlo actuar abiertamente como un Estado capitalista a favor del capital. Así, plantea que "más que sólo saturar el significado y el contenido de la democracia con valores de mercado, el neoliberalismo ataca los principios, las prácticas, las culturas, los sujetos y las instituciones de la democracia entendida como el gobierno del pueblo".

1 GUILLEMÍ, Rubén. La democracia pierde atractivo en la región: la mayoría no la prefiere como forma de gobierno, La Nación, Buenos Aires, 9 nov. 2018. https://www.lanacion.com.ar/2189854-lademocracia-pierde-atractivo-en-la-region-la-mayoria-no-la-prefiere-como-form 
El neoliberalismo frecuentemente es presentado por sus defensores como una concepción prevalecientemente económica centrada en políticas de y para el mercado que, como señala Wacquant (2011), están marcadas por "la desregulación laboral, la movilidad del capital, la privatización, un programa monetario de deflación y autonomía financiera, la liberalización del comercio, la competencia entre zonas y la reducción de la tributación y los gastos públicos" (p.13). Sin embargo, esta visión acotada y reduccionista intenta ocultar que en realidad se trata de "un proyecto político transnacional destinado a reconstruir el nexo del mercado, del Estado y de la ciudadanía desde arriba” (p.13).

Cuando nos referimos al establishment económico y financiero aludimos a los grupos de empresarios y ejecutivos de grandes bancos y empresas, políticos y administradores que operan desde dentro del Estado en favor de los intereses de esos grupos y a funcionarios y expertos de organizaciones internacionales de diverso tipo como la Organización para la Cooperación y el Desarrollo Económico (OCDE), la Organización Mundial del Comercio (OMC), Banco Interamericano de Desarrollo (BID), Fondo Monetario Internacional (FMI), Banco Mundial (BM), Unión Europea (UE) y Organización de Estados Iberoamericanos (OEI) que, entre otras definiciones, vienen condicionando líneas de financiamiento a la aceptación de sus recomendaciones respecto de las políticas educativas que deberán ser impulsadas por los gobiernos de nuestros países.

Así, el neoliberalismo contemporáneo "es, ante todo, un proyecto económico-político de clase y no solamente un programa de políticas públicas" (PUELLO-SOCARRÁS, 2013, p. 17-19). Podemos afirmar que existe una gobernanza neoliberal (una racionalidad rectora) que elimina la distinción entre las empresas estatales, de negocios, sin fines de lucro y no gubernamentales no sólo en la forma de una alianza público-privado -presente desde los años ochenta del siglo XX y que se conoce como Nueva Gestión Pública-, sino sobre todo por un modelo de negocios que impregna todas estas organizaciones y estructuras político-sociales. En palabras de Brown (2017, p. 164), "gobernanza incluye y señala una fusión importante de las prácticas políticas con las de negocios, tanto en el nivel administrativo como en el de provisión de bienes y servicio". Implica un modo específico de gobierno y expresa mucho más que el acto de gobernar, así como la participación de una amplia variedad de agentes no estatales en el gobierno.

La gobernanza neoliberal supone, entonces, un cambio en la conceptualización del poder, de la práctica y de su administración. El poder se torna disperso y relacional, tal como lo definiera Foucault, característica que es explotada en beneficio propio por todos aquellos grupos que participan del gobierno en sentido amplio. Así, el neoliberalismo cambia la noción de lo político 
inscribiéndola en la lógica del campo gerencial o administrativo eliminando, de este modo, el componente de antagonismo y hostilidad que constituye lo político, es decir, la condición misma de existencia de la democracia y del respeto al pluralismo. La gobernanza neoliberal se propone desplazar los enfrentamientos y las pasiones a la esfera privada, en lugar de movilizarlas.

Reducida a su forma procedimental, la democracia -como propone Brown (2017)-, se configura como un régimen diferente y separado de la política, vaciándola de participación ciudadana en la medida en que los agentes no intervienen en la definición de parámetros y restricciones en el acceso a los recursos y bienes, ni en las tendencias que siguen las políticas públicas.

La repercusión de esta racionalidad neoliberal en las reformas educativas está marcada por la introducción de cambios en el sistema educativo orientados hacia a) la incorporación en el funcionamiento de los centros escolares de la gestión empresarial; b) la creciente flexibilización, descentralización y desregulación; c) el énfasis en la autonomía escolar entendida como apuesta por la diversidad de ofertas educativas y por la libertad de elección de los usuarios; d) la promoción del sujeto educativo siempre en curso y empresario de sí. (JODAR y GÓMEZ, 2017, p. 399)

La sociogénesis neoliberal da lugar tanto a nuevas relaciones sociales como también a la producción de otras formas de subjetividad ya que, como resalta Laval (2018, p. 2), la introducción por todas partes de mecanismos, relaciones y comportamientos de mercado, "supone que los sujetos se vuelvan otros de lo que son, que se vuelvan sujetos emprendedores, 'empresarios de sí mismos"'. Así, Laval (2018, p. 14) entiende que,

en el capitalismo neoliberal, el sujeto está convocado a no resistirse a la intensificación de un trabajo, tiene que conformarse, transformarse, mejor reformarse para estar consigo mismo y con los demás en una relación de explotación. El proceso de ultra-subjetivación no es un sometimiento a una ley externa impuesta por un capital capaz de disponer de la fuerza de trabajo, es una forma de moldear desde el interior del sujeto todas las reglas, particularmente sociales, a partir del momento en que es el sujeto mismo el que deviene capital, que se impone a sí mismo una relación capital-trabajo, que mantiene consigo una relación de explotación. Es, en resumen, un medio extraordinario para aumentar la plusvalía absoluta que hace del sujeto una empresa, es decir, que hace de la relación consigo una relación de explotación, una relación del plus extra, de siempre más.

La performatividad específica del marco político neoliberal vigente -signado por la globalización económica y de las comunicaciones- impulsa el crecimiento de la competitividad y la exigencia al máximo de la productividad de los cuerpos produciendo un nuevo orden de trabajo, incluido el trabajo 
docente. Es decir, se produce una intensificación de las actividades exigidas en el desempeño laboral de profesores y profesoras, a la vez que un aumento en los tipos de control y vigilancia alrededor de su actuación individual.

Un análisis en Latinoamérica permite comprender cómo las tecnologías de gobierno de orientación neoliberal procuran orientar los comportamientos de las y los docentes, señalando aquellas capacidades que deben demostrar en relación con sí mismos y con el sistema institucional, indicando lo que deberán realizar para mejorar su actuación docente y, de esta manera, conservar su puesto de trabajo. Esta gubernamentalidad se inscribe en un proceso de reestructuración de las relaciones de trabajo en el sistema educativo cuya tendencia es a la eliminación progresiva de conquistas, normas protectoras y garantías laborales. La forma laboral flexible tiene como fin aumentar el rendimiento de las y los docentes, y ponerlos al servicio de los nuevos objetivos económicos y sociales de la escuela. Es preciso señalar que ya desde la década del 90 las reformas y políticas educativas en Brasil y Argentina iniciaron un proceso de reconfiguración del trabajo docente desde una lógica gerencialista, cuya consolidación estamos viendo en la actualidad (FELDFEBER y ANDRADE DE OLIVEIRA, 2004; DUHALDE y FELDFEBER, 2016).

Las tecnologías políticas neoliberales en educación no son simplemente vehículos para cambios administrativos, organizacionales y/o técnicos, involucran mecanismos para reformar la educación pública y cambiar los significados atribuidos a la identidad docente, poniendo en juego discursos que se orientan a reformular las representaciones que las y los docentes poseen sobre sí mismos, sus comportamientos y las relaciones que establecen con otros docentes. Así, a la par de la mercantilización de la educación, marcada por la predominancia de conceptos como calidad de la educación y educabilidad, se ha ido afianzando el desfinanciamiento de la educación (CULLEN, 2007) y cambios en las regulaciones y condiciones del trabajo docente con la consiguiente reconfiguración del puesto de trabajo.

\section{GOBIERNO DE LA EDUCACIÓN, MERCADO Y TRABAJO DOCENTE EN LAS POLÍTICAS NEOLIBERALES}

La forma mercado o empresarial se ha difundido como narrativa maestra definiendo las relaciones en la trama del Estado, la sociedad y la economía, extendiéndose hacia el campo escolar, tanto en la formación y el trabajo docente como para la educación de niños, niñas y jóvenes. Las políticas educativas neoliberales inscriptas en el mercado están reemplazando a aquellas que son propias de un Estado de tipo keynesiano centradas en el bienestar de la población, 
dando lugar a la reducción y reestructuración del Estado cuyas funciones van siendo "ocupadas" por otras empresas y asociaciones que se especializan en ofrecer servicios educativos. En este marco, las políticas educativas se van consolidado alrededor de, por lo menos, seis grandes líneas de acción:

a) institucionalización del paradigma evaluativo: establecimiento de indicadores de productividad y rendimiento del alumnado y del profesorado;

b) privatización de la gestión política y administrativa de la educación: el neogerencialismo o "neomanagement" (JODAR y GÓMEZ, 2017, p. 390) y la alianza público-privadas política y administrativa del Estado en vinculación con organizaciones no gubernamentales, fundaciones y empresas;

c) cultura emprendedora: optimización de docentes y estudiantes en tanto empresarios de sí mismos y sus efectos en la formación y el trabajo docente;

d) (auto)gobierno y vigilancia de las emociones: la gestión y (auto) control de los sujetos de la educación a través de las psicologías positivas y la educación emocional.

Este conjunto de tecnologías que el neoliberalismo pone en juego, para incorporar una racionalidad política de gobierno propia del sector privado y del gerencialismo empresarial al campo de la educación pública y del trabajo docente, se completa con otras dos que resultan centrales, a saber, la reestructuración presupuestaria y las políticas de confrontación y desacreditación de los sindicatos de trabajadores y trabajadoras.

\section{a) EVALUACIÓN, PRODUCTIVIDAD Y RENDIMIENTO DEL ALUMNADO Y DEL PROFESORADO}

La estrategia de situar a las/los docentes como las/los principales responsables de la "crisis educativa" expresada a través de los "malos resultados" se enarbola para justificar la urgencia de una reconfiguración del sector público. En las últimas décadas, diversas denominaciones tales como escuelas eficientes, instituciones educativas de calidad, efecto-escuela, escuelas efectivas, mejora escolar, entre otras, han sido puestas en circulación para designar lo que se entiende por una buena educación en las escuelas, teniendo como fuente principal la medición de los resultados surgidos de la aplicación de evaluaciones, tanto sobre el desempeño de profesores y profesoras como de los aprendizajes del alumnado. Informes cuantitativos y cualitativos producidos por el Estado, centros de investigación y fundaciones de diverso tipo, han sido diseñados a partir de recomendaciones, criterios y formatos emanados de organismos internacionales como Programa de las Naciones Unidas para el Desarrollo (PNUD), Organización 
para la Cooperación y el Desarrollo Económico (OCDE), Organización de las Naciones Unidas para la Educación, la Ciencia y la Cultura (UNESCO), Banco Mundial (BM) y Unión Europea (UE), entre los principales.

El paradigma evaluador ubica a las y los docentes como responsables centrales del proceso educativo a cargo de la gestión del aula y de las instituciones escolares. A este fin, deben reorganizar y aprovechar al máximo los recursos, reducir el desorden y diseñar actividades para el alumnado que puedan realizarse de manera autónoma, individualmente o en grupo, incluyendo aprendizajes prácticos, a fin de incrementar los logros educativos. Éstos últimos deben ser resultados tangibles, es decir, medibles y observables a través de pruebas estandarizadas y otros tipos de seguimiento verificables.

Así, la evaluación se vincula a dos cuestiones principales:

- al sostenimiento del puesto de trabajo que requiere la producción de un cuerpo dócil que internalice el orden laboral que restringe y/o elimina conquistas, normas protectoras y garantías laborales y,

- a los cambios en los saberes y objetivos de la formación y la práctica docente, lo que implica un cambio epistémico y de las aptitudes que se procuran desarrollar y que involucran también al alumnado.

La información generada a partir de la implementación de dispositivos de evaluación del profesorado es utilizada para comparar, clasificar y direccionar comportamientos, prácticas y destinos, pero, junto a esto, también introduce la reconfiguración de las escuelas y del sistema escolar público en general, inscribiéndolas dentro de lógicas basadas en el rendimiento productivo y la eficiencia en la relación costo-beneficio, lo que pone en evidencia un giro en dirección a la construcción de un mercado escolar.

El carácter omnipresente del paradigma evaluativo impugna sistemáticamente la posición de los discursos educativos críticos alrededor del mundo, colocando a los resultados de las pruebas aplicadas como único parámetro legítimo para dar cuenta de una buena escolarización. Los dispositivos de evaluación constituyen poderosos mecanismos de control externo que, a través de la clasificación, generan un control de sí y afectan la relación con otros. Un/a buen/a docente se convierte en aquel o aquella que responde al sistema rindiendo cuentas de sus saberes y capacidades frente a los exámenes y prescripciones que los rigen. En este nuevo escenario, cada uno "es protagonista y responsable de su propio aprendizaje" para lo cual debe "conectarse a sus propios recursos personales” (BALL, 2013). Evaluación significa rendir cuentas periódicamente acerca de las propias capacidades, poniéndose a disposición, sin cuestionar sus herramientas y, sobre todo, acatando el orden de los resultados como la verdad sobre el sí mismo y su acción (MARTÍNEZ, 2018). 
La evaluación como política educativa trae aparejada, en lo que concierne a los individuos, la producción de una subjetividad en relación de competencia con otros. Se debe ganar demostrando, una y otra vez, de forma adecuada a las regulaciones y tecnologías que controlan la productividad y en los términos en que lo hacen, que se posee las cualidades para ocupar el puesto de trabajo (esforzado, emprendedor, positivo) y más que otros “competidores". Pero también establece las lógicas del trabajo privado en lo público, como destacan Sisto y Fardella (2011, p. 128),

\begin{abstract}
el sistema de evaluación docente se constituye en un dispositivo concreto que busca no sólo evaluar cumplimiento de estándares de desempeño, sino que instala la lógica del trabajo privado en el campo de lo público. Así, la consideración individual del desempeño, la incorporación de incentivos económicos individualizados, y la instalación de modelos de desarrollo de carrera de carácter emprendedor, emergen como nuevos referentes para comprender el trabajo del profesor en el ámbito de la educación pública.
\end{abstract}

El punto de vista que se pretende imponer al focalizar en la evaluación oculta todo un entramado de relaciones en la manera en que se configuran no sólo el trabajo docente y el oficio de alumno/a sino las escuelas y las aulas en la trama del sistema escolar, así como también las familias, la comunidad y la vida social en general, al impulsar y favorecer las relaciones de competencia entre estudiantes, docentes, escuelas y sistemas educativos.

La competencia, la eficiencia y la productividad constituyen los ejes para forjar las nuevas identidades para lo cual es preciso producir cambios en la subjetividad de las y los docentes. Además, requiere que sean poseedores de un rasgo central, "ser capaces de vivir en la incertidumbre", entendiendo a su puesto de trabajo como su propio emprendimiento y, así, alejándolos de la condición de trabajador/trabajadora asalariado/asalariada integrante de una clase o colectivo social (LUENGO NAVAS y SAURA CASANOVA, 2013, p. 146). Aquí, entonces, están la culpa, la incertidumbre, la inestabilidad y la emergencia que darán lugar a una nueva subjetividad, a un nuevo tipo de profesor y profesora.

\title{
b) PRIVATIZACIÓN Y NEOGERENCIALISMO EN LA EDUCACIÓN PÚBLICA
}

El discurso gerencialista justifica que las políticas educativas neoliberales se sostienen en las demandas de la sociedad expresando que no son, de este modo, el resultado de ningún tipo de imposición, de ninguna conminación social. Este discurso ha sido central dado que, como señala Ball (2003), está inscribiendo la cultura empresarial competitiva en el campo escolar, lo que erosiona "los regímenes 
profesionales y éticos que han sido dominantes en las escuelas y la instauración, en su reemplazo, de regímenes empresariales, competitivos. Esto involucra 'procesos de institucionalización y desinstitucionalización’ (LOWDNES, 1997, p. 61)” (p. 90).

El neogerencialismo impregnará el campo de la gestión y administración del Estado proponiéndose -destacan Alonso y Fernández Rodríguez (2016, p. 9)- como "un modelo de dirección que favorezca la libertad de acción frente a las burocracias y los sindicatos, desechando rasgos asociados a estos últimos como la estabilidad o la rutina", introduciendo en las distintas áreas del Estado la denominada "cultura de la empresa" y, en particular, a la gestión empresarial para superar la "enfermedad" que representa, en la visión neoliberal, la burocracia estatal.

\begin{abstract}
Así, del principio de autoridad legítima socialmente regulada -típica del ciclo de gobernabilidad burocrática- con el uso del concepto de governance se pasa al de intercambio de intereses y recursos entre esferas públicas y privadas, legitimado por la mayor eficiencia y rentabilidad para todas las partes. Este cambio de los modelos de legitimación se justifica como una gerencia postpolítica de los asuntos públicos, y vuelve a proponer la imagen de la red (red de asociaciones públicas y privadas, del tercer sector y las empresas), esta vez como activadora del intercambio y la movilización de recursos, fundamentalmente económicos (RHODES, 1997). (ALONSO y FERNÁNDEZ RODRÍGUEZ, 2016, p. 13).
\end{abstract}

De este modo, la nueva gestión empresarial instalada en el campo estatal abrió las puertas a nuevos procesos de privatización en educación. Una forma endógena de privatización suele presentarse como el camino hacia la modernización de la educación y la gestión escolar. Por privatización en la educación o endógena, Ball y Youdell (2007, p. 13) aluden "a esas formas de privatización (que) implican la importación de ideas, métodos y prácticas del sector privado a fin de hacer que el sector público se asemeje cada vez más a una empresa y sea 'tan eficiente' como una empresa". En este sentido, la difusión de la educación para el emprendimiento recientemente integrada a los diseños curriculares de países latinoamericanos es impulsada por organismos internacionales y empresas dentro de un paradigma educativo global, con el fin de formar docentes que enseñen al alumnado a convertirse en productores que puedan generar un resultado tangible, es decir, que posea rendimiento económico (DUHALDE y FELDFEBER, 2016, p. 100).

La privatización de la educación o exógena refiere a la apertura de la educación pública en función de los intereses del sector privado "a través de modalidades basadas en el beneficio económico" y "en cuanto a la concepción, la gestión o la provisión de diferentes aspectos de la educación pública” (BALL y 
YOUDEL, 2007, p. 13). Un ejemplo extremo que evidencia dramáticamente las consecuencias de la privatización exógena del Estado es la República de Haití. Esta nación se convirtió en uno de los países con mayor número de organizaciones no gubernamentales $(\mathrm{ONG})$ y fundaciones, sobre todo provenientes del mundo anglosajón, a partir del terremoto del 12 de enero de 2010. Esta masiva presencia no sólo no ha cambiado la baja calidad de vida de la población haitiana, sino que muestra cómo progresivamente dichas organizaciones han ido apropiándose de funciones del Estado y fondos públicos. Lindon (2019) expone cómo la sociedad haitiana, que ha vivido por décadas en una pobreza multidimensional, vio al Estado transformarse en débil e incompetente a la vez que se multiplicaron las organizaciones no gubernamentales, lo que ha llevado a que Haití sea llamada "la

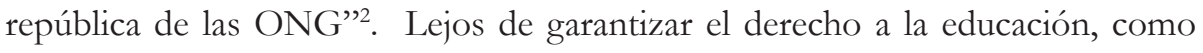
un derecho social, se ha convertido en un privilegio, en un lujo o un negocio de algún sector u organización impidiendo la constitución de una sociedad más justa y equitativa.

En Argentina, la tendencia privatizadora, intensificada en el período 2016-2019, promovió la alianza público-privada que supone la vinculación del sector público con empresas del sector privado. Esta "alianza” se presenta como la herramienta "ideal" para la mejora de, entre otros sectores, la educación, estimulada fundamentalmente por el Banco Mundial dando lugar, por ejemplo, a contratos de Participación Público-Privada (PPP). De esta manera, se establece una relación contractual entre un gobierno, que pone a disposición el financiamiento y la infraestructura del sector público y, los proveedores privados, que ven en la educación un negocio de alta rentabilidad. La influencia del vínculo públicoprivado no se limita a la provisión de infraestructura escolar, tecnología e insumos, sino que también se dirige a incidir en las políticas educativas en lo relativo al desarrollo de contenidos escolares, y, muy especialmente, en la formación y capacitación docente (SEOANE, 2018; RODRIGUEZ, 2019).

\section{c) CULTURA EMPRENDEDORA Y FORMACIÓN DEL SUJETO-EMPRESA EN LA ESCUELA}

La preponderancia de la mirada económica en el neoliberalismo hace que ésta se traslade a todas las actividades humanas. El homo oeconomicus en el neoliberalismo -propone Heffes (2014, p. 83) apoyándose en M. Foucault- “es el

\footnotetext{
2 CASCANTE, Manuel. M. Haití, la república de las ONG, ABC.es, Madrid, 25 nov. 2010. https:// www.abc.es/20101125/internacional/haiti-republica-20101125.html Esta noticia planteaba que, para la época, las casi diez mil agencias no gubernamentales en Haití representaban un Estado paralelo con un presupuesto cercano al PBI del país.
} 
hombre consumidor, es el hombre de empresa y de la producción" con el fin de constituir una "sociedad de productores". Esta lógica hace posible que todo sea considerado un mercado regido por el principio de competencia. El productor ejemplar es empresario de sí mismo, ya que "se autoproduce, se 'mejora', se hace más competitivo", en suma, "realiza un gobierno de sî" (HEFFES, 2014, p. 84). El sujeto-empresa no se sale de sí mismo en la actual sociedad neoliberal que "configura a los seres humanos de modo exhaustivo como actores del mercado, siempre, solamente y en todos los lados como homo oeconomicus" (BROWN, 2017, p. 36). Hablar de sujeto emprendedor significa que "el homo oeconomicus neoliberal toma la forma de capital humano para fortalecer su posicionamiento competitivo y aprecia su valor como una figura de intercambio o interés" (BROWN, 2017, p. 40-41).

La lógica mercadocéntrica impone una nueva forma de homogeneización centrada en la productividad y el consumo que apela a transformaciones de la subjetividad de los individuos, ampliando las desigualdades. En la producción de esa subjetividad neoliberal advertimos renovadas prácticas de exclusión y estigmatización social, la expulsión de lo distinto como lo denomina Han (2017). La pregunta es entonces, ¿qué formas de subjetividad propician las políticas neoliberales, qué saberes son puestos en juego para producirlas y por qué el sistema educativo es considerado clave para alcanzarlas? Esto supone también que otras formas de subjetividad deben ser desechadas o excluidas. Lo decisivo -o crucial- es que la subjetividad, como punto de intersección entre el yo y el poder, se ha convertido en campo de batalla, como remarca Ball (2015).

La producción de subjetividad, desde un punto de vista histórico y social, presupone la incorporación de los sujetos a formaciones socioculturales específicas. La figura del docente emprendedor (teacherpreneur) en el discurso dominante de la política educativa neoliberal reafirma una organización de la vida social que otorga centralidad a que los individuos se consideren empresarios de sí mismos (DÍEZ GUTIÉRREZ, 2015). De este modo, cuando los gobiernos expresan que pretenden "volver a poner al maestro o profesor en el centro de la sociedad", se corresponde con la adquisición de habilidades emprendedoras.

A fin de argumentar que el emprendedorismo es la forma cultural contemporánea por excelencia, los gobiernos latinoamericanos auspician estudios y realizan acuerdos con fundaciones y empresas que confirman que la cultura emprendedora se encuentra presente en las prácticas de las generaciones más jóvenes, como algo que "ya viene con ellas" (CÉSAR y DE VILLALOBOS, 
2014, p. 5). Así, por ejemplo, el programa Junior Achivement ${ }^{3}$, en palabras de su director general Eduardo Marty, es un instrumento educativo cuyos objetivos son la formación de buenos empresarios y consumidores frente a la evidente crisis de la educación, a la obsolescencia de las prácticas pedagógicas y a la desvinculación de los conocimientos escolares con la vida (IMEN, 2012: 4; DUHALDE y FELDFEBER, 2016). Dicha fundación tiene como objetivo "enseñar a los empleados, a los aprendices más jóvenes de sus empresas como funciona la mente de un entrepreneur,que sin nada, sin máquinas, sin herramientas, sin capital, sin materia prima, sin nada, logra desarrollar una empresa." (IMEN, 2012: 40)

Durante el año 2018, el gobierno de Brasil y la empresa Junior Achievement testearon el curso de emprendedorismo en 15 escuelas técnicas federales, según informaba un medio periodístico ${ }^{4}$, señalando que un sondeo de opinión demostraba que $60 \%$ de los brasileños deseaban ser sus propios patrones y más del $11 \%$ ya poseían sus propios emprendimientos. La retórica neoliberal afirma que los conocimientos vinculados al emprendedorismo constituyen una "necesidad social" pero que se encuentran ausentes o no disponibles en las instituciones educativas. De este modo, desde el discurso político es instalado como un contenido central del currículo de las escuelas y de la formación docente.

De este modo, bajo el supuesto que el espíritu emprendedor ya está inscripto en la cultura contemporánea y en los cuerpos, debe quedar exento de cualquier crítica o resistencia dado que significa una separación del sí mismo. Estos nuevos modos de especificación de los sujetos de gobierno -como destaca Rose (2007, p. 125)-, "en términos de una ética de la actividad y de la iniciativa individualmente entendida", establecen una separación entre quienes son "considerados ciudadanos competentes y aquellos que no lo son". A través de la figura del emprendedor como modelo civilizatorio se establece una práctica divisoria entre afiliados y marginales. Permanecen afiliados quienes logran emprender la propia vida, "calcular sus acciones en términos de una inversión en sí mismos, en sus familias, y maximizar esta inversión en referencia a los códigos de sus comunidades particulares"; y marginales, aquellos incapaces "para gestionarse a sí mismos como sujetos", y a quienes forman parte de "algún tipo de anticomunidad cuya moralidad, estilo de vida o comportamiento se consideran una amenaza o un impedimento para la satisfacción pública y el orden político" (ROSE, 2007, p. 129-130).

3 Junior Achievement "es la fundación de educación económica y de negocios más antigua del mundo, más grande y de mayor crecimiento. Fue fundada en 1919 por Horace Moses, presidente de Strathmore Paper Co, y Theodore Vail, presidente de AT\&T.” (IMEN, 2012, p. 40)

4 DE SOUSA PINTO, Ana Estela. Em educação emprendedora Brasil fica em $57^{\circ}$ entre 65 países, Folha de São Paulo, San Pablo, 6 enero 2018. Disponible en: https://www1.folha.uol.com.br/mercado/2018/01/1946996em-educacao-empreendodora-brasil-fica-em-57-entre-65-paises.shtml 
Las tareas son de autorregulación y autovigilancia -como resalta HAN (2017, p. 37-38)- "el imperativo de la autenticidad fuerza al yo a producirse a sí mismo", siendo la "forma neoliberal de producción del yo", "el yo como empresario de sí mismo se produce, se representa y se ofrece como mercancía". Si la relación entre el yo y el poder es donde se produce la subjetividad (ROSE, 1989 apud BALL, 2013, p. 112), el actual proyecto de dominación trata de fabricar sujetos que vivan sus vidas como un emprendimiento del yo, "sin importar cuán pequeño, pobre o sin recursos sea", "cada aspecto de la existencia humana se produce como empresarial” (BROWN, 2017, p. 82).

\section{d) AUTOGOBIERNO Y VIGILANCIA DE LAS EMOCIONES EN LA VIDA ESCOLAR}

La difusión de la educación emocional y el clima escolar en las escuelas públicas y la formación docente constituye el abordaje elegido desde las tecnologías psi positivas y de autoayuda para introducir cambios en los objetivos educativos y de los contenidos de formación y orientación del trabajo docente en las políticas neoliberales. Su influencia en las políticas públicas dirigidas al sistema educativo se hizo cada vez más perceptible, hasta llegar a las aulas y a los espacios de formación y capacitación docente de América Latina. Durante los últimos años, las corrientes del pensamiento positivo y la inteligencia emocional se han diseminado a través de carreras cortas, cursos, conferencias, talleres y capacitaciones presenciales y en línea (MARTÍNEZ, 2019).

Sin embargo, es preciso preguntarnos -siguiendo a Han (2014, p. 65)- ¿de dónde viene este repentino interés por las emociones?. Las llamadas psicologías positivas o del "yo" vinculadas a corrientes de las neurociencias proponen teorías de aprendizaje que se enfocan en los rasgos emocionales individuales calificados como positivos y en los aspectos motivacionales con el objetivo de buscar la "auténtica" felicidad. Estas corrientes de pensamiento dominan ampliamente la formación de recursos humanos en el ámbito empresarial y de negocios. Martin Seligman (1998) y Albert Ellis (2008), principales referentes de la psicología positiva y de la psicoterapia cognitiva llevan adelante un método de "entrenamiento optimista" (modelo ABCDE) que se aplica en escuelas no sólo de Estados Unidos sino también en países europeos. Se trata de incrementar el optimismo, poniendo en práctica el rebatimiento de los pensamientos pesimistas o "irracionales", aprendiendo a discutir con nosotros mismos y, de esa manera, reformulando las creencias para "dar un giro positivo a la vida". 
La revitalización de las psicologías del yo o positivas, así como los discursos de autoayuda y de elementos ligados a ellas como la psicoterapia, proponen como tópico central la responsabilidad que debe asumir la persona a la hora de diseñar o redefinir sus condiciones emocionales en particular y su proyecto de vida en general. Esta autorregulación se articula en torno a tres puntos básicos: «hacerse cargo de uno mismo», «amarse a uno mismo» y «respetarse a uno mismo». Esto implica que una persona puede inscribirse en un proyecto de vida autorrealizado o en otro que no lo sea, haciéndose cargo de esa elección. La propia persona es responsable de su felicidad y de ningún modo debe trasladar dicha responsabilidad al entorno o hacerla depender de otros (AMPUDIA de HARO, 2006).

En la actual retórica educativa neoliberal, la educación emocional se considera la variable de mayor peso en la vida escolar, más que cualquier otra y que determina todas las otras, al punto de señalar que cuestiones como la cantidad de libros en la biblioteca escolar o el número de alumnos a cargo de cada docente o la infraestructura escolar, están subordinadas a las emociones en juego, de forma que las condiciones pedagógicas y de trabajo escolar dependen de nuestras capacidades emocionales. Un docente emocionalmente educado aprende a ser "realista", "positivo" y a "fluir" desarrollando un autocontrol de las emociones, automotivándose y ejerciendo un control sobre otros agentes escolares, no dando lugar a pensamientos negativos ni a aquellos considerados "desafiantes", minimizando "la vulnerabilidad de la persona a determinadas disfunciones (estrés, depresión, impulsividad, agresividad, etc.) o prevenir su ocurrencia”. (BISQUERRA ALZINA, 2005, p. 97)

La emoción aquí "representa un medio muy eficiente para el control psicopolítico del individuo” (HAN, 2014, p. 75). Así, no se le dice directamente al sujeto que aumente la eficiencia, la rentabilidad y la competitividad, se apela a su emocionalidad, a la gestión de su propio yo (BALL, 2013, p. 2015). Se trata de «tecnologías del yo» que conducen a la persona a efectuar por sí misma una serie de operaciones sobre sus ideas, sentimientos y comportamientos, provocando una transformación conducente a la obtención de un cierto grado o estado de bienestar o felicidad. Las narrativas de autoayuda y autorrealización tienden un puente entre la emocionalidad y la eficiencia económica (ILLOUZ, 2010).

El homo oeconomicus u homo redemptoris es siempre un individuo, no un grupo, ni un comité, ni una organización, no hay colectivo asociado porque la competencia es la forma de relación por excelencia entre seres humanos que abordan todo como un mercado, no puede pensar ni en propósitos públicos ni en problemas comunes de manera política (BROWN, 2017). Motivación, liderazgo, gestión, emprendedorismo, inteligencia emocional, coaching, comunicación asertiva, reprogramación positiva, indagación apreciativa, entre otras, suponen teorías y 
prácticas que no tiene nada de transparente, sino que, bien por el contrario, a través de narrativas que aluden a la felicidad, al bienestar y a la armonía, ocultan una concepción de sujeto humano que, finalmente, sólo es visto y puede verse a sí mismo como homo oeconomicus (HEFFES, 2014; MARTÍNEZ, 2019).

\section{A MODO DE CIERRE}

El neoliberalismo es un proyecto político transnacional que reconstruye la relación del Estado con el mercado y es conducido por una clase dirigente global compuesta por expertos de organizaciones internacionales, funcionarios y empresarios que se apropia del Estado para operar en favor de sus intereses condicionando, de este modo, las políticas públicas a la aceptación de sus recomendaciones. La racionalidad política neoliberal se despliega bajo la forma de un modelo de negocios que impregna el Estado y las estructuras políticosociales, es decir, implica un modo específico de gobernar la sociedad. Cuando sólo existe el homo oeconomicus y cuando la esfera de lo político mismo se expresa en términos económicos, se desvanece el fundamento para una ciudadanía preocupada con las cosas públicas y el bien común. En esto, el problema no es sólo que el neoliberalismo elimine los fondos para los bienes públicos y devalúe los fines comunes, aunque en efecto esto ocurra, sino que la ciudadanía misma pierde su valencia y lugar políticos.

En el campo de la educación, los organismos internacionales junto a fundaciones y organizaciones no gubernamentales (ONG) proponen un sistema de evaluación que opera como dispositivo de control de estudiantes y docentes, y refuerza una lógica de la competencia entre alumnas y alumnos, profesores y profesoras, escuelas y sistemas públicos de educación. Las diferentes modalidades de privatización exógena y endógena ponen en riesgo el derecho a la educación de niñas, niños y jóvenes. Estas tendencias privatizadoras convirtieron a la República de Haití en el caso más extremo de captura del Estado por parte de organismos internacionales y ONG. La educación se convierte en un privilegio y bien de consumo para quienes cuentan y son capaces de demostrar que están en condiciones de acceder a ella y, a su vez, conforma un "negocio" del que participa una clase dirigencial proveniente de las empresas. Es así como la educación deja de ser un derecho social garantizado por el Estado y se manipula como un objeto transable en los mercados internacionales en los que opera el sector financiero que busca, a través de la venta de servicios y productos educativos, incrementar sus ganancias. 
El neoliberalismo despliega un conjunto de tecnologías de gobierno y tecnologías del yo necesarias para producir, por un lado, un sentido común arraigado en la idea de que lo público conforma una maquinaria costosa e ineficiente que debe ser intervenido y modificado y, por otro, una nueva subjetividad sometida y explotada que se reconoce como sujeto emprendedor, empresario de sí, y mantiene una relación de explotación consigo mismo y se auto infringe la máxima exigencia para la producción de un orden que reconfigura el trabajo docente. Productividad, intensificación, control y vigilancia operan como dispositivos de sujeción de la subjetividad neoliberal con el propósito de maximizar el rendimiento de las alumnas y alumnos como también de las profesoras y profesores.

La gestión de las emociones como mecanismo de control se dirige a engendrar la sumisión necesaria al aumento de la productividad de un cuerpo individual. Bajo esa presión del rendimiento el sujeto puede no percibir la explotación, pero cuando toma conciencia de ella, cualquier expresión de crítica, malestar o disconformidad respecto de decisiones, contenidos o situaciones de trabajo son calificadas como negativas, irracionales o pesimistas. Así, se van eliminando progresivamente las resistencias surgidas en un contexto político de vulneración de derechos y de pérdida de condiciones de trabajo de las y los docentes.

De modo que cualquier forma de organización colectiva, sea en la forma de alianzas sindicales, sindicatos o asociaciones gremiales, es caracterizada por el discurso neoliberal como una amenaza y un obstáculo para alcanzar la calidad del sistema educativo. Un objetivo final es que la fuerza laboral desaparezca como categoría, desestimulando y debilitando paulatinamente la asociación entre trabajadores y trabajadoras de la educación, dando lugar a una profundización de la enajenación y la explotación.

La educación pública bajo el gobierno neoliberal se propone producir subjetividades sumisas, se dirige a destruir e impedir todo pensamiento, acción crítica, organización colectiva que denuncie y resista las formas de opresión y explotación que se vienen instalando en el campo de la educación pública. Aquí es donde hoy nos encontramos, cobijando convicciones, esperanzas y luchas que disputen el sentido de la educación pública contra el poder neoliberal.

\section{BIBLIOGRAFÍA}

ALONSO, Luis E. y FERNANDEZ RODRIGUEZ, Carlos J. La burocracia neoliberal y las nuevas funciones de las normas, Encrucijadas Revista Crítica de Ciencias Sociales, Vol.12, 2016, a1201. 
AMPUDIA DE HARO. Fernando Administrar el yo: literatura de autoayuda y gestión del comportamiento y los afectos. Reis Revista española de investigaciones sociológicas, 113, pp. 49-72, 2006. Disponible a [https:// dialnet.unirioja.es/descarga/articulo/1993709.pdf]

BALL, Stephen J. Subjectivity as a site of struggle: refusing neoliberalism?, British Journal of Sociology of Education, 2015. Disponible a [http://dx.doi. org/10.1080/01425692.2015.1044072]

BALL, Stephen Performatividad y fabricaciones en la economía educacional: rumbo a una sociedad performativa. Pedagogía y Saberes, 0(38), pp. 103-113, 2013. Disponible a [http://dx.doi.org/10.17227/01212494.38pys103.113].

BALL, Stephen Profesionalismo, gerencialismo y reformatividad. Revista Educación y Pedagogía, 15(37), 87-104, 2003. Disponible a [http:// aprendeenlinea.udea.edu.co/revistas/index.php/revistaeyp/article/view/5979]

BALL, Stephen \& YOUDELL, Doudell. Privatización encubierta en la educación pública. Internacional de la Educación V Congreso Mundial, Berlín (Alemania) Informe preliminar, 2007. Disponible en: https://www. joanmayans.com/privatizacion_encubierta_de_la_educacion_publica.pdf

BISQUERRA ALZINA, Rafael La educación emocional en la formación del profesorado. Revista Interuniversitaria de Formación de Profesorado, Universidad de Zaragoza, España Vol. 19, núm. 3, diciembre, pp. 95-114, 2005. Disponible a: [http://redalyc.uaemex.mx/src/inicio/ArtPdfRed. jsp?iCve $=27411927006$ ]

BROWN, Wendy El pueblo sin atributos: la secreta revolución del neoliberalismo. Barcelona: Malpaso Ediciones, 2017. 2da Edición.

CESAR, Rubén \& DE VILLALOBOS, Gonzalo E1 Desarrollo Emprendedor y la Escuela Media. La mirada de los jóvenes de la Ciudad Autónoma de Buenos Aires. Dirección General de Evaluación de la Calidad Educativa, GCBA, noviembre, pp. 1-6, 2014. Disponible a [http://www.agroindustria. gob.ar/sitio/areas/escuelagro/_archivos//000011_El\%20desafio $\% 20 \mathrm{de} \% 20$ emprender/000000_El\%20desarrollo\%20emprendedor\%20en\%20escuela $\% 20$ media.pdf] 
CULLEN, Carlos Resistir con inteligencia. Reflexiones éticas sobre educación. México: Pueblo Nuevo, 2007.

DUHALDE, Miguel A. \& FELDFEBER, Myriam (coord.) Tendencias privatizadoras de y en la educación argentina. Ciudad Autónoma de Buenos Aires: Confederación de Trabajadores de la Educación de la República Argentina - CTERA, 2016. Disponible a [https://ei-ie.org/media_gallery/ c8d89a990223f9690a6847886c5c4b30.pdf]

DÍEZ GUTIÉRREZ, E. J. La educación de la nueva subjetividad neoliberal. Revista Iberoamericana de educación, 68, pp. 157-172, 2015.

ELLIS, Albert. Ser Feliz: Y vencer las preocupaciones. España: Ed. Obelisco, 2008.

FELDFEBER, Myriam \& ANDRADE DE OLIVEIRA, Dalila (comps.) Políticas educativas y trabajo docente: nuevas regulaciones ¿nuevos sujetos? Buenos Aires: Ediciones Noveduc, 2004.

HAN, Byung-Chul. Psicopolítica. Buenos Aires: Ed. Herder, 2014.

La expulsión de lo distinto: percepción y comunicación en la sociedad actual. Buenos Aires: Herder Editorial, 2017.

HEFFES, Omar Darío Biopolítica: entre el homo economicus neoliberal y la "sociedad del espectáculo". El Banquete de los Dioses, Revista de Filosofía y Teoría Política Contemporáneas, Volumen 1, N 1, noviembre-mayo; pp. 66-68, 2013-2014.

ILLOUZ, Eva La salvación del alma moderna: terapia, emociones y la cultura de la autoayuda. Buenos Ares: Katz Editores, 2010.

IMEN, Pablo Junior Achievement o la pedagogía del capital. Realidad Económica, 271, $1^{\circ}$ de octubre/15 de noviembre; pp. 28-50, 2012. 
JODAR, Francisco y GÓMEZ, Lucía Educación posdisciplinaria, formación de nuevas subjetividades y gubernamentalidad neoliberal. Herramientas conceptuales para un análisis del presente, Revista Mexicana de Investigación Educativa, enero-marzo, año/vol. 12, n 032, COMIE, Distrito Federal, México; pp.3 81404.

LAVAL, Christian Antropología del sujeto neoliberal. La Libertad de Pluma Revista Digital, Red Zadig Argentina, Año 1, Ed. 4, pp. 1-20, noviembre, 2018. Disponible en: http://lalibertaddepluma.org/christian-laval-antropologia/?pdf=1595

LINDON, Moïse Políticas públicas, pobreza y analfabetismo de personas jóvenes y adultas en Haití. Revista Interamericana de Educación de Adultos, v. 41, n. 1, p. 7-34, 12 jan. 2019.

LUENGO NAVAS, Julián y SAURA CASANOVA, Geo La performatividad en la educación. La construcción del nuevo docente y el nuevo gestor performativo. REICE. Revista Iberoamericana sobre Calidad, Eficacia y Cambio en Educación, 11 (3), pp.139-153, 2013.

MARTINEZ, Ma. E. La figura del docente emprendedor, el paradigma evaluativo y la escolarización en la lógica instrumental del neoliberalismo, Actas del IV Seminario Nacional de la Red ESTRADO Argentina "La regulación del trabajo y la formación docente en el siglo XXI". Ciudad de Buenos Aires, Facultad de Filosofía y Letras/UBA: 2018.

MARTINEZ, Ma. E. “Todo depende de ti”: educación emocional para la dominación neoliberal. Revista Maíz, $\mathrm{N}^{\circ}$ 11, Facultad de Periodismo y Comunicación Social, Universidad Nacional de La Plata, 2019. Disponible en: https://www.revistamaiz.com.ar/2019/09/todo-depende-de-ti.html

PUELLO-SOCARRÁS, José F. Ocho tesis sobre el Neoliberalismo (1973-2013), en RAMÍREZ, Hernán (org.) O neoliberalismo sul-americano em clave transnacional: enraizamento, apogeu e crise. São Leopoldo: Oikos; Editora Unisinos, 2013. (Coleção Estudos Históricos LatinoAmericanos - EHILA) E-book, PDF - vol. 1, pp.13-57 
RODRÍGUEZ, Laura R. Las alianzas Estado/empresas para la mejora de la educación en Argentina a principios del siglo XXI: de la filantropía a la incidencia sobre la política educacional. Revista Brasileira de Política e Administração da Educação - Periódico científico editado pela ANPAE, [S.l.], v. 35, n. 1, p. 015 - 033, maio 2019. Disponível em: <https://seer.ufrgs.br/rbpae/article/ view/89877>.

ROSE, Nikolas ¿La muerte de lo social? Re-configuración del territorio de gobierno. Revista Argentina de Sociología, año 5, No 8, pp. 111-150, 2007.

SELIGMAN, Martin. Aprenda optimismo. España: Ed. Grijalbo, 1998.

SEOANE, Viviana. Reconfiguración neoliberal del sistema educativo argentino: gestión empresarial de la escuela y profesionalización docente, Actas del IV Seminario Nacional de la Red ESTRADO Argentina "La regulación del trabajo y la formación docente en el siglo XXI". Ciudad de Buenos Aires, Facultad de Filosofía y Letras/UBA: 2018.

SISTO, Vicente y FARDELLA, Carla Nuevas Políticas Públicas, Epocalismo e Identidad: El caso de las políticas orientadas a los docentes en Chile. Revista de Estudios Universitarios, 37 (1), 123-141, 2011.

WACQUANT, Loïc. Forjando el Estado Neoliberal: Workfare, Prisonfare e Inseguridad Social. Revista Prohistoria: historia, políticas de la historia, Rosario, v. 16, dic. 2011.

\section{María Elena Martínez}

Doutora em Ciências Humanas - Educação (PUC-Rio). Professora Titular da Universidad Nacional de La Plata - Argentina. Coordenadora da RedEstrado Argentina. E-mail: maeunlp@gmail.com

\section{Viviana Isabel Seoane}

Doutora em Ciências Sociais (FLACSO/Argentina). Professora adjunta da Universidad Nacional de La Plata - Argentina. E-mail: viviseoane@gmail.com. E-mail: maeunlp@gmail.com 